\title{
Multiple biological effects of secondary metabolites of Ziziphus jujuba: isolation and mechanistic insights through in vitro and in silico studies
}

\author{
Didem Şöhretoğlu ${ }^{1} \cdot$ Sevda Deniz Bakır ${ }^{1} \cdot$ Burak Barut $^{2} \cdot$ Michal Šoral $^{3,4} \cdot$ Suat Sari $^{1}$
}

Received: 12 November 2021 / Revised: 13 December 2021 / Accepted: 18 December 2021 / Published online: 8 January 2022

(c) The Author(s), under exclusive licence to Springer-Verlag GmbH Germany, part of Springer Nature 2022

\begin{abstract}
In this study, we tested tyrosinase and $\alpha$-glucosidase effects of different extracts of Ziziphus jujuba fruits. The $n$-BuOH subextract inhibited both tyrosinase and $\alpha$-glucosidase $\left(\mathrm{IC}_{50}=18.82 \pm 1.13\right.$ and $25.03 \pm 0.77 \mu \mathrm{g} / \mathrm{mL}$, respectively) better than the positive controls kojic acid and acarbose $\left(\mathrm{IC}_{50}=58.26 \pm 0.25\right.$ and $46.10 \pm 2.3 \mu \mathrm{g} / \mathrm{mL}$, respectively). Thus, the $n-\mathrm{BuOH}$ extract was selected for further phytochemical studies. Indole-3-lactic acid methylester, catechin, magnoflorine, kaempferol 3-O- $\alpha$-rhamnopyranosyl-( $1 \rightarrow 6)-\beta$-galactopyranoside, quercetin 3-O- $\alpha$-rhamnopyranosyl-( $1 \rightarrow 6)-\beta$-galactopyranoside, and procyanidin B4 were isolated from the extract. We tested $\alpha$-glucosidase and tyrosinase inhibitory effects, as well as DNA nuclease effects of the isolated compounds. Procyanidin B4 exhibited the best activity against both tyrosinase and $\alpha$-glucosidase $\left(\mathrm{IC}_{50}=60.25 \pm 0.88\right.$ and $170.18 \pm 5.60 \mu \mathrm{g} / \mathrm{mL}$, respectively). The isolates did not show any nuclease effect at increasing concentrations. Molecular docking studies provided insights into inhibition mechanisms of the isolates against tyrosinase and $\alpha$-glucosidase at the molecular level.
\end{abstract}

Keywords Tyrosinase $\cdot \alpha$-Glucosidase $\cdot$ Jujube $\cdot$ Procyanidin B4 $\cdot$ Magnoflorine $\cdot$ Molecular docking

\section{Introduction}

Ziziphus jujuba Mill. (Rhamnaceae) is known as "jujube" or "Chinese date" and is distributed mainly in Asia and Europe. In addition to its nutritional value, this fruit is also used for different medicinal purposes including treatment of sleep disorders, diabetes, gastrointestinal problems, beautify the skin, and boosting the immune system [1,2].

Tyrosinase (polyphenol oxidase) enzyme catalyzes the hydroxylation of L-tyrosine to 3,4-dihydroxy-L-phenylalanine (L-DOPA) and oxidation of L-DOPA to dopaquinone

Didem Şöhretoğlu

didems@ hacettepe.edu.tr

1 Department of Pharmacognosy, Faculty of Pharmacy, Hacettepe University, TR-06100 Ankara, Turkey

2 Department of Biochemistry, Faculty of Pharmacy, Karadeniz Technical University, TR-61080 Trabzon, Turkey

3 Analytical Department, Slovak Academy of Sciences, Institute of Chemistry, Dúbravská cesta 9, 84538 Bratislava, Slovak Republic

4 Central Laboratories, Faculty of Chemical and Food Technology, Slovak University of Technology in Bratislava, Radlinského 9, 81237 Bratislava, Slovak Republic using molecular oxygen. Then, dopaquinone produces biopigments such as melanin, which plays an important role in the protection of skin from UV damage. However, the excessive production of melanin causes some skin problems. Moreover, melanin occurrence in the brain is also related to neurodegenerative disorders like the Parkinson's disease. Tyrosinase triggers the browning of fruits and vegetables resulting in a decrease of their nutritional value. The development of new tyrosinase inhibitors is of great interest due to their application potential in food, cosmetic, and pharmaceutical industries [3].

Diabetes mellitus (DM) is characterized by hyperglycemia which further leads to chronic complications affecting various organs including eyes, blood vessels, and nerves. In turn, it may decrease overall health resulting in a reduced quality of life. Globally, diabetes is among the top 10 causes of death and a serious threat to health. Despite the availability of a variety of drugs for diabetes treatment, due to their side effects, there is still a huge demand for the development of new, safe, and cost-effective anti-diabetic agents [4].

Ziziphus jujuba fruit is regarded as a cheap, readily applicable, and available product with several benefits including anti-diabetic effects. Investigating $Z$. jujuba fruit for these benefits may lead to promising extracts 
and isolates with medical and nutritional potential $[1,2]$. Thus, in this work, we focused on screening of Z. jujuba and its isolates for their inhibitory effects on $\alpha$-glucosidase and tyrosinase enzymes. For this purpose, we prepared methanol $(\mathrm{MeOH})$, petroleum ether $(\mathrm{PE})$, and n-butanol $(n-\mathrm{BuOH})$ extracts from the fruits of the plant. Phytochemical investigations on the most active $n$ - $\mathrm{BuOH}$ extract led to the isolation of kaempferol-3- $O$ - $(\alpha$-rhamnopyranosyl $(1 \rightarrow 6)$ - $\beta$-galactopyranoside) (1), quercetin-3-O- $(\alpha-$ rhamnopyranosyl $(1 \rightarrow 6)-\beta$-galactopyranoside) $(2)$, catechin (3), procyanidin B4 (4), indole-3-lactic acid methylester (5), and magnoflorine (6) (Fig. 1). Furthermore, we tested their enzyme inhibitory effects and their ability to induce DNA damage. In an effort to understand the mechanism of the tyrosinase inhibitory effect, in silico molecular docking studies were performed to assess the affinity of the active compounds for key residues. Furthermore, druglikeness and ADMET (Absorption, Distribution, Metabolism, Excretion, Toxicity) profiles of compounds were evaluated.

\section{Materials and methods}

Ziziphus jujuba fruits were collected in September 2019 from Amasya (Middle Black Sea Region), Anatolia, Turkey. A voucher specimen has been deposited in the Herbarium of the Faculty of Pharmacy, Hacettepe University, Ankara, Turkey (HUEF 19071). Polyamide, LiChroprep C18, and Sephadex LH-20 for column chromatography, and all the solvents used for chromatography were purchased from Sigma. Thin-layer chromatography analyses were carried out on pre-coated Kieselgel 60 F254 aluminum plates (Merck). Compounds were detected by UV fluorescence and spraying $1 \%$ vanillin/ $\mathrm{H}_{2} \mathrm{SO}_{4}$, followed by heating at $100{ }^{\circ} \mathrm{C}$ for 1-2 min. 1D- and 2D-NMR measurements were recorded in MeOD- $d 4$ at room temperature on a Varian VNMRS 600 NMR spectrometer (Palo Alto, CA) $\left({ }^{1} \mathrm{H} 600\right.$ and ${ }^{13} \mathrm{C}$ $151 \mathrm{MHz}$ ). The chemical shift scales were calculated using the resonance frequency of tetramethylsilane (TMS) as the reference.

\section{Extraction and isolation}

Fresh pulps of $Z$. jujuba (4 kg) were chopped and then extracted with $\mathrm{MeOH}(3 \times 3 \mathrm{~L})$ at room temperature by stirring with a magnetic stir bar for $8 \mathrm{~h}$ and filtered afterwards. The combined $\mathrm{MeOH}$ extracts were concentrated under reduced pressure. The resultant extract was then dissolved in $\mathrm{H}_{2} \mathrm{O}$ and the water-soluble portion was partitioned with petroleum ether $\left(40-60{ }^{\circ} \mathrm{C}\right)(\mathrm{PE})(2 \times 150 \mathrm{~mL})$ and $n-\mathrm{BuOH}(4 \times 150 \mathrm{~mL})$, consecutively. The $n-\mathrm{BuOH}$ extract $(10.7 \mathrm{~g})$ was chromatographed over a polyamide column [vacuum liquid chromatography (VLC), $120 \mathrm{~g}$,
$44 \times 3.5 \mathrm{~cm}$ ], eluting with gradient $\mathrm{MeOH} / \mathrm{H}_{2} \mathrm{O}$ mixtures $(0-100 \%)$ to afford nine main fractions (Frs A-J). Fr B (140 mg) was chromatographed over a silica gel column $(44 \times 1.3 \mathrm{~cm})$ eluting stepwise with a $\mathrm{CHCl}_{3}: \mathrm{MeOH}$ mixture and four fractions (Frs $\mathbf{B}_{\text {I-IV }}$ ) were collected. Fr $\mathbf{B}_{\text {II }}$ $(6.8 \mathrm{mg})$ was rechromatographed by Sephadex LH-20 column using $\mathrm{MeOH}$ and magnoflorine $(3.2 \mathrm{mg}$ ) was obtained. Fr D (302 mg) was subjected to C18 (VLC) eluting with a stepwise $\mathrm{H}_{2} \mathrm{O}-\mathrm{MeOH}$ gradient $(10-60 \% \mathrm{MeOH})$ to obtain catechin $(17.3 \mathrm{mg})$, kaempferol-3- $\boldsymbol{O}$-( $\boldsymbol{\alpha}$-rhamnopyranosyl $(\mathbf{1} \rightarrow \mathbf{6})$ - $\beta$-galactopyranoside) $(6.2 \mathrm{mg})$, and indole-3-lactic acid methylester (2.6 mg). Fr F (360 mg) was chromatographed over C18-VLC eluting with a stepwise $\mathrm{H}_{2} \mathrm{O}-\mathrm{MeOH}$ gradient (10-60\% $\mathrm{MeOH})$ and Frs $\mathbf{F}_{\text {I-IV }}$ were obtained. Fr F $_{\text {III }}$ was further purified by Sephadex LH-20 CC using $\mathrm{MeOH}$ as mobile phase to obtain quercetin-3- $\boldsymbol{O}-(\boldsymbol{\alpha}-$ rhamnopyranosyl $(\mathbf{1} \rightarrow \boldsymbol{6})$ - $\beta$-galactopyranoside) $(3.0 \mathrm{mg})$. Fr H $(1205.2 \mathrm{mg})$ was applied to a C18-VLC $(42 \times 2.5 \mathrm{~cm})$ eluting with a stepwise $\mathrm{H}_{2} \mathrm{O}-\mathrm{MeOH}$ gradient $(20-40 \%)$ and four subfractions were obtained (Frs $\mathbf{H}_{\text {I-IV }}$ ). Further separation of Fr $\mathbf{H}_{\text {II }}$ with Sephadex LH-20 CC $(1.6 \times 39 \mathrm{~cm})$ using $\mathrm{MeOH}$ provided Procyanidin B4 (18.0 mg).

\section{Inhibitory effects of a-glucosidase from Saccharomyces cerevisiae}

The $\alpha$-glucosidase inhibitory effect assays of the extracts/ isolated compounds were carried out employing the colorimetric methods according to our previous studies [5]. The positive control was acarbose (Sigma, A8980). The inhibitory properties were examined in 96-well plates, and the absorbance was measured at $405 \mathrm{~nm}$ using a Multiskan ${ }^{\mathrm{TM}}$ Go Microplate Spectrophotometer. Briefly, the reaction mixture containing $50 \mu \mathrm{L}$ of the extracts/isolated compounds in phosphate buffer ( $\mathrm{pH}$ 6.8) containing dimethyl sulfoxide (final concentration $1 \%$ ), and $100 \mu \mathrm{L}$ of $0.5 \mathrm{U} / \mathrm{mL} \alpha$-glucosidase (Sigma, G5003) were preincubated for $15 \mathrm{~min}$ at room temperature. Then, the substrate, $50 \mu \mathrm{L}$ of $5 \mathrm{mM} 4$-nitrophenyl $\alpha$-D-glucopyranoside (4- $p$ NPG) (Sigma, 487,506), was added to the mixture. The $\alpha$-glucosidase inhibitory properties of the extracts/isolated compounds were examined by the following formula: Inhibition $(\%)=\left[\left(A_{\text {control }}-A_{\text {sample }}\right) /\right.$ $\left.\left(A_{\text {control }}\right)\right] \times 100 . A_{\text {control }}$ is the activity of the enzyme without extracts/isolated compounds, while $\mathrm{A}$ is the activity of the enzyme with extracts/isolated compounds. The $\mathrm{IC}_{50}$ values were calculated from the inhibition (y-axis)-concentration, ( $x$-axis) curve plotting against the extracts/isolated compound concentrations.

\section{Inhibitory effects of tyrosinase from mushroom}

The tyrosinase inhibitory effect assays of the extracts/ isolated compounds were carried out employing the 
colorimetric methods according to our previous studies [6]. The positive control was kojic acid (Sigma, K3125). The inhibitory properties were examined in 96-well plates, and the absorbance was measured at $475 \mathrm{~nm}$ using Multiskan ${ }^{\mathrm{TM}}$ Go Microplate Spectrophotometer. Briefly, the reaction mixture containing $120 \mu \mathrm{L}$ of the extracts/isolated compounds in phosphate buffer ( $\mathrm{pH}$ 6.8) containing dimethyl sulfoxide (final concentration 1\%), and $20 \mu \mathrm{L}$ of $250 \mathrm{U} / \mathrm{mL}$ tyrosinase (Sigma, T3824) were preincubated for $15 \mathrm{~min}$ at room temperature. Afterwards, the substrate, $20 \mu \mathrm{L}$ of $3 \mathrm{mM}$ 3,4-dihydroxy-L-phenylalanine (L-DOPA) (Sigma, D9628), was added to the mixture to start the enzymatic reaction. The tyrosinase inhibitory properties of the extracts/isolated compounds were evaluated using the same formula as for the $\alpha$-glucosidase inhibitory effects.

Lineweaver-Burk and Dixon plots were used to determine the inhibitory type and constant $\left(K_{i}\right)$ of the most potent compound against tyrosinase [7]. In this study, mixtures with a range of substrate (L-DOPA) solution concentrations (2.5, 5.0 , and $7.5 \mathrm{mM}$ ) and a constant concentration of the enzyme $(250 \mathrm{U} / \mathrm{mL})$ in the absence and presence of compound 4 with diverse concentrations were analyzed at room temperature. The kinetic data were analyzed using Microsoft Excel 2010.

\section{Plasmid DNA damage effects}

The plasmid DNA damage properties of isolated compounds were analyzed employing the agarose gel electrophoresis according to our previous studies [8]. The results were monitored by a BioRad Gel Doc XR system and analyzed using Image Lab Version 4.0.1 Software Program. Briefly, the reaction mixture [isolated compounds in Tris- $\mathrm{HCl}$ buffer (50 mM, pH 7) containing dimethyl sulfoxide (final concentration 1\%), supercoiled pBR322 plasmid DNA (Thermo Scientific, SD0041)] were preincubated for $30 \mathrm{~min}$ at $37^{\circ} \mathrm{C}$. Afterwards, loading buffer (bromophenol blue) (0.2\%) (Sigma, B0126), xylene cyanol (0.2\%) (Sigma, X4126), glycerol (30\%) (Sigma, G5516), and sodium dodecyl sulfate (4.5\%) (Sigma, L3771) were added to the samples. The samples were loaded on $0.8 \%$ (w/v) agarose (Sigma, A9539) gel with ethidium bromide (Sigma, E7637) staining in Tris-acetic acid-EDTA (TAE) (1X) buffer. Electrophoresis was performed at $100 \mathrm{~V}$ for $90 \mathrm{~min}$ using Wide Mini ReadySub-Cell GT Horizontal Electrophoresis System (BioRad).

\section{Molecular modelling}

Compounds were modelled and optimized using LigPrep (2021-2, Schrödinger LLC, New York, NY) and MacroModel (2021-2, Schrödinger LLC, New York, NY) according to OPLS4 forcefield parameters [9] and conjugate gradient method. Ionization and tautomeric states of the compounds were also generated during ligand preparation.
Molecular descriptors and pharmacokinetic parameters were calculated using QikProp (2021-2, Schrödinger LLC, New York, NY) and SwissADME portal (www.swissadme.ch) [10]. Mushroom tyrosinase structure (PDB code: $2 \mathrm{Y} 9 \mathrm{X}$ resolution: $2.78 \AA$ ) [11] was downloaded from the RCSB Protein Data Bank (www.rcsb.org) [12] and prepared using the Protein Preparation Wizard of Maestro (2021-2, Schrödinger LLC, New York, NY)[13]. The preparation process includes removal of redundant molecules, addition of hydrogen atoms and partial charges, setting ionization states of the residues, and optimization of hydrogen bonds. The active site grids of the receptor were generated using the Receptor Grid Generation panel of Maestro (central coordinates $-10.00,-29.00,-43.92$; volume: $27,000 \AA^{3}$ ). Molecular docking was performed using Glide (2021-2, Schrödinger LLC, New York, NY) at extraprecision (XP) mode with 50 runs per ligand [14]. The results were evaluated visually and the selected ligand-receptor complex for each compound was subjected to MM-GBSA calculations using Prime MM-GBSA panel (2021-2, Schrödinger LLC, New York, NY) [15], which was run using VSGB solvation model according to OPLS4 forcefield parameters. Receptor residues up to $5.0 \AA$ from ligand were kept flexible and minimization was selected as sampling method in MM-GBSA calculations. The pharmacophore model of 4-tyrosinase complex from MM-GBSA was created using Phase 2021-2, Schrödinger LLC, New York, NY) with e-pharmacophore method by setting distance cut-off $2.0 \AA$ between different feature types and $4.0 \AA$ between same feature types, and creating receptor-based excluded volume shells [16].

\section{Statistical analysis}

The data were analyzed using GraphPad Prism 5.0 and Microsoft Excel 10. The data were expressed as mean \pm standard deviation $(n=3)$. Statistical analyses were performed according to one-way analysis of variance (oneway ANOVA) and Tukey test.

\section{Results and discussion}

\section{Isolation and structure elucidation}

1D and 2D-NMR spectroscopy was the key method used for the structural elucidation of the isolated compounds. The structural constraints obtained by a manual analysis of the chemical shift values, signal multiplicities, integral values, and most importantly, 2D homonuclear and heteronuclear correlations, were sufficient enough to provide almost unambiguous identification of all compounds. Compounds were identified as kaempferol-3$O$-( $\alpha$-rhamnopyranosyl $(1 \rightarrow 6)-\beta$-galactopyranoside $)$ 
(1) $[17]$, quercetin-3- $O-(\alpha-$ rhamnopyranosyl $(1 \rightarrow 6)-\beta$-galactopyranoside) (2) [18], catechin (3) [19], procyanidin B4 (4) [20], indole-3-lactic acid methylester (5) [21], and magnoflorine (6) [22]. The individual NMR data reports of $\mathbf{4}$ are given in below, 1-3, and 5-6 are given in Supplementary material. Moreover, NMR spectra of $\mathbf{4}$ are given in Supplementary material.

\section{NMR data of 4}

\section{Procyanidin B4 (4)}

The compound was found to be present in a dynamic equilibrium between two rotameric forms in a ratio 100:75.

Major form: ${ }^{1} \mathrm{H}$ NMR $\left(\mathrm{CD}_{3} \mathrm{OD}, 600 \mathrm{MHz}\right): \delta_{\mathrm{H}}=7.09(\mathrm{~d}$, $J=1.9 \mathrm{~Hz}), 1 \mathrm{H}), 6.99(\mathrm{~d}, J=2.0 \mathrm{~Hz}, 1 \mathrm{H}), 6.85-6.88(\mathrm{~m}$, $2 \mathrm{H}), 6.80(\mathrm{~d}, 8.0 \mathrm{~Hz}, 1 \mathrm{H}), 6.78(\mathrm{~d}, J=8.2 \mathrm{~Hz}, 1 \mathrm{H}), 5.96(\mathrm{~s}$, $1 \mathrm{H}), 5.84(\mathrm{~d}, J=2.4 \mathrm{~Hz}, 1 \mathrm{H}), 5.80(\mathrm{~d}, J=2.4 \mathrm{~Hz}, 1 \mathrm{H}), 4.94$ (br s, $1 \mathrm{H}), 4.63(\mathrm{~d}, J=7.9 \mathrm{~Hz}, 1 \mathrm{H}), 4.58(\mathrm{dd}, J=9.7,7.9 \mathrm{~Hz}$, $1 \mathrm{H}), 4.42(\mathrm{~d}, J=9.7 \mathrm{~Hz}, 1 \mathrm{H}), 4.22-4.24(\mathrm{~m}, 1 \mathrm{H}), 2.93$ (dd, $J=16.9,4.3 \mathrm{~Hz}, 1 \mathrm{H}), 2.83(\mathrm{ddd}, J=16.9,2.5,0.9 \mathrm{~Hz}, 1 \mathrm{H})$ ppm; ${ }^{13} \mathrm{C}$ NMR $\left(\mathrm{CD}_{3} \mathrm{OD}, 151 \mathrm{MHz}\right): \delta_{\mathrm{C}}=158.69,157.51$, $157.30,156.36,155.87,155.39,146.47,146.13,145.95$, $145.64,132.45,132.26,121.19,119.11,116.29,116.04$, 115.96, 115.25, 108.73, 107.21, 99.44, 97.58, 97.54, 96.13, 83.86, 80.01, 73.80, 67.42, 38.87, 30.08 ppm.

Minor form: ${ }^{1} \mathrm{H}$ NMR $\left(\mathrm{CD}_{3} \mathrm{OD}, 600 \mathrm{MHz}\right): \delta_{\mathrm{H}}=6.72$ $(\mathrm{d}, J=8.2 \mathrm{~Hz}, 1 \mathrm{H}), 6.70(\mathrm{~d}, J=2.0 \mathrm{~Hz}, 1 \mathrm{H}), 6.68(\mathrm{~d}$, $J=2.2 \mathrm{~Hz}, 1 \mathrm{H}), 6.61(\mathrm{~d}, J=8.2 \mathrm{~Hz}, 1 \mathrm{H}), 6.45$ (ddd, $J=8.2$, $2.2,0.7 \mathrm{~Hz}, 1 \mathrm{H}), 6.42(\mathrm{dd}, J=8.2,2.0 \mathrm{~Hz}, 1 \mathrm{H}), 6.10(\mathrm{~s}, 1 \mathrm{H})$, $5.94(\mathrm{~d}, J=2.4 \mathrm{~Hz}, 1 \mathrm{H}), 5.89(\mathrm{~d}, J=2.4 \mathrm{~Hz}, 1 \mathrm{H}), 4.81(\mathrm{br}$ s, $1 \mathrm{H}), 4.46(\mathrm{dd}, J=6.3,1.7 \mathrm{~Hz}, 1 \mathrm{H}), 4.34-4.29(\mathrm{~m}, 2 \mathrm{H})$, 4.05-4.07 (m, 1H), $2.87(\mathrm{dd}, J=17.0,5.1 \mathrm{~Hz}, 1 \mathrm{H}), 2.71$ (ddd, $J=17.0,2.3,0.8 \mathrm{~Hz}, 1 \mathrm{H}) \mathrm{ppm} ;{ }^{13} \mathrm{C} \mathrm{NMR}\left(\mathrm{CD}_{3} \mathrm{OD}\right.$, $151 \mathrm{MHz}): \delta_{\mathrm{C}}=158.55,157.27,157.20,156.30,155.80$, $155.39,146.04,145.60,145.58,145.56,132.57,131.71$, $120.46,120.25,116.44,116.05,115.93,114.81,108.28$, 107.40, 101.48, 97.70, 97.13, 96.38, 84.05, 79.92, 73.84, $67.80,38.76,29.37 \mathrm{ppm}$.

\section{a-Glucosidase inhibitory effects of extracts/isolated compounds}

The extracts showed $\alpha$-glucosidase inhibition actions with $\mathrm{IC}_{50}$ values ranging from $25.03 \pm 0.77$ to $69.50 \pm 3.60 \mu \mathrm{g} / \mathrm{mL}$ (see Table 1). Among the tested extracts, the $n$-BuOH extract $(25.03 \pm 0.77 \mu \mathrm{g} / \mathrm{mL})$ and water extract $(35.00 \pm 2.40 \mu \mathrm{g} / \mathrm{mL})$ exhibited higher inhibitory effect than that of acarbose as a positive control $(46.10 \pm 2.30 \mu \mathrm{g} / \mathrm{mL})$. The isolated compound 4 exhibited weak $\alpha$-glucosidase inhibitory effects with $\mathrm{IC}_{50}$ value of $170.18 \pm 5.60 \mu \mathrm{M}$, while $\mathrm{IC}_{50}$ values of other compounds were above $250 \mu \mathrm{g} / \mathrm{mL}$. These results suggest
Table 1 The $\mathrm{IC}_{50}$ values of the extracts and isolated compounds on $\alpha$-glucosidase and tyrosinase

\begin{tabular}{lll}
\hline Sample & $\begin{array}{l}\alpha \text {-Glucosidase } \\
\mathrm{IC}_{50}(\mu \mathrm{g} / \mathrm{mL})\end{array}$ & $\begin{array}{l}\text { Tyrosinase } \\
\mathrm{IC}_{50}(\mu \mathrm{g} / \mathrm{mL})\end{array}$ \\
\hline MeOH extract & $69.50 \pm 3.60$ & $29.75 \pm 1.12^{* * * *}$ \\
PE extract & $59.26 \pm 1.30$ & $22.76 \pm 1.18^{* * *}$ \\
BuOH extract & $25.03 \pm 0.77 * * *$ & $18.82 \pm 1.13^{* * *}$ \\
Water extract & $35.00 \pm 2.40^{* *}$ & $27.20 \pm 0.49 * * *$ \\
$\mathbf{1}$ & $>250$ & $>250$ \\
$\mathbf{2}$ & $>250$ & $>250$ \\
$\mathbf{3}$ & $>250$ & $\mathrm{nd}$ \\
$\mathbf{4}$ & $170.18 \pm 5.60$ & $60.25 \pm 0.88$ \\
$\mathbf{5}$ & $>250$ & $190.32 \pm 6.26$ \\
$\mathbf{6}$ & $>250$ & $161.22 \pm 7.21$ \\
Kojic acid & - & $58.26 \pm 0.25$ \\
Acarbose & $46.10 \pm 2.30$ & - \\
\hline
\end{tabular}

${ }^{* *} P<0.001 ; * * * P<0.0001 \mathrm{nd}$ : Not determined

that the $n-\mathrm{BuOH}$ extract had the strongest inhibitory effect probably due to the synergistic effects of its components.

\section{Tyrosinase inhibitory effects of extracts/isolated compounds}

The observed $\mathrm{IC}_{50}$ values of the extracts/isolated compounds are given in Table 1 . The $\mathrm{IC}_{50}$ values of the extracts/isolated compounds ranged from $18.82 \pm 1.13$ to $29.75 \pm 1.12 \mu \mathrm{g} / \mathrm{mL}$. The obtained results showed that the extracts had noticeable inhibitory actions against tyrosinase. Notably, the tested extracts had higher tyrosinase inhibitory effects than kojic acid as a positive control $(58.26 \pm 0.25 \mu \mathrm{g} / \mathrm{mL})$. Among the isolated compounds, 4 exhibited the best inhibitory properties with $\mathrm{IC}_{50}$ value of $60.25 \pm 0.88 \mu \mathrm{M}$ against tyrosinase. Also, the $\mathrm{IC}_{50}$ values of $\mathbf{5}$ and $\mathbf{6}$ were calculated as $190.32 \pm 6.26$ and $161.22 \pm 7.21 \mu \mathrm{M}$, respectively.

The kinetic parameters on the active compounds against tyrosinase were analyzed by Lineweaver-Burk and Dixon plots (Fig. 2A, B). As presented in Figs. 2A, 4 induced a competitive inhibition of the tyrosinase enzyme. The $V_{\max }$ value was similar upon increasing inhibitor and substrate concentrations and was calculated to be $312.50 \mu \mathrm{M} / \mathrm{min}$. It is well known that this compound binds to the active site of the enzyme with this inhibition type [23]. Also, the $K_{i}$ value of 4 was determined as $30.50 \pm 0.20 \mu \mathrm{M}$ according to the Dixon plot (Fig. 2B). Tyrosinase inhibitory potential of $Z$. jujuba was investigated by Song et al., and they indicated a condensed tannin mixture exhibited tyrosinase inhibitory properties [24]. Our study is consistent with the study of Song et al., we further isolated and identified that a condensed tannin, and $\mathbf{4}$ exhibited good tyrosinase inhibition. 
<smiles>C[C@@H]1O[C@H](OC[C@H]2O[C@@H](Oc3c(-c4ccc(O)cc4)oc4cc(O)cc(O)c4c3=O)[C@H](O)[C@H](O)[C@@H]2O)[C@H](O)[C@H](O)[C@H]1O</smiles><smiles>C[C@H]1O[C@H](OC[C@H]2O[C@@H](Oc3c(-c4ccc(O)c(O)c4)oc4cc(O)cc(O)c4c3=O)[C@H](O)[C@@H](O)[C@@H]2O)[C@H](O)[C@@H](O)[C@@H]1O</smiles><smiles>Oc1cc(O)c2c(c1)O[C@H](c1ccc(O)c(O)c1)[C@H](O)C2</smiles><smiles>COC(=O)C(O)Cc1c[nH]c2ccccc12</smiles>

5<smiles>C=C1CC[N+](C)(C)[C@H]2Cc3ccc(OC)c(O)c3-c3c(C)ccc1c32</smiles>

Fig. 1 Structures of isolated compounds 


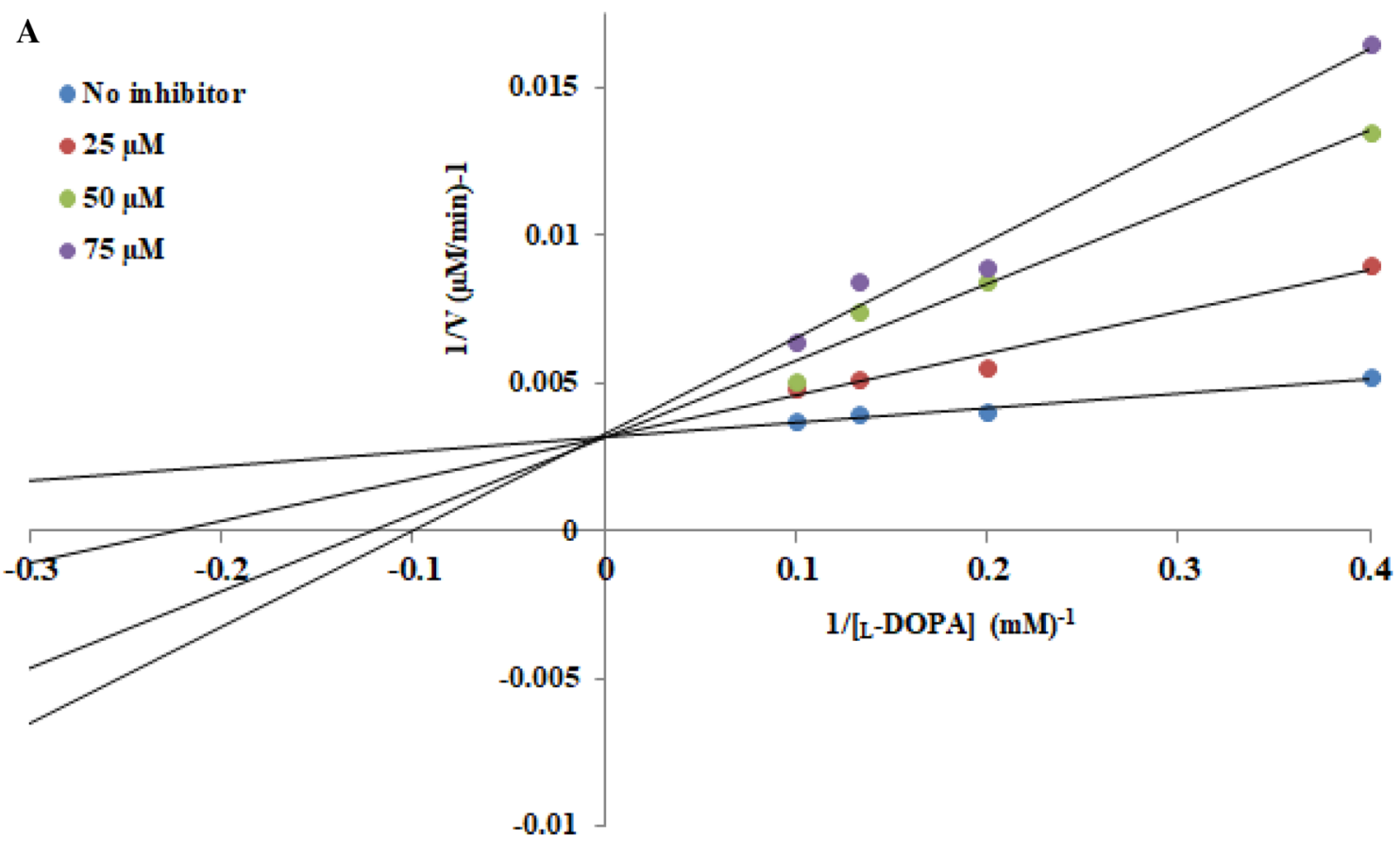

B

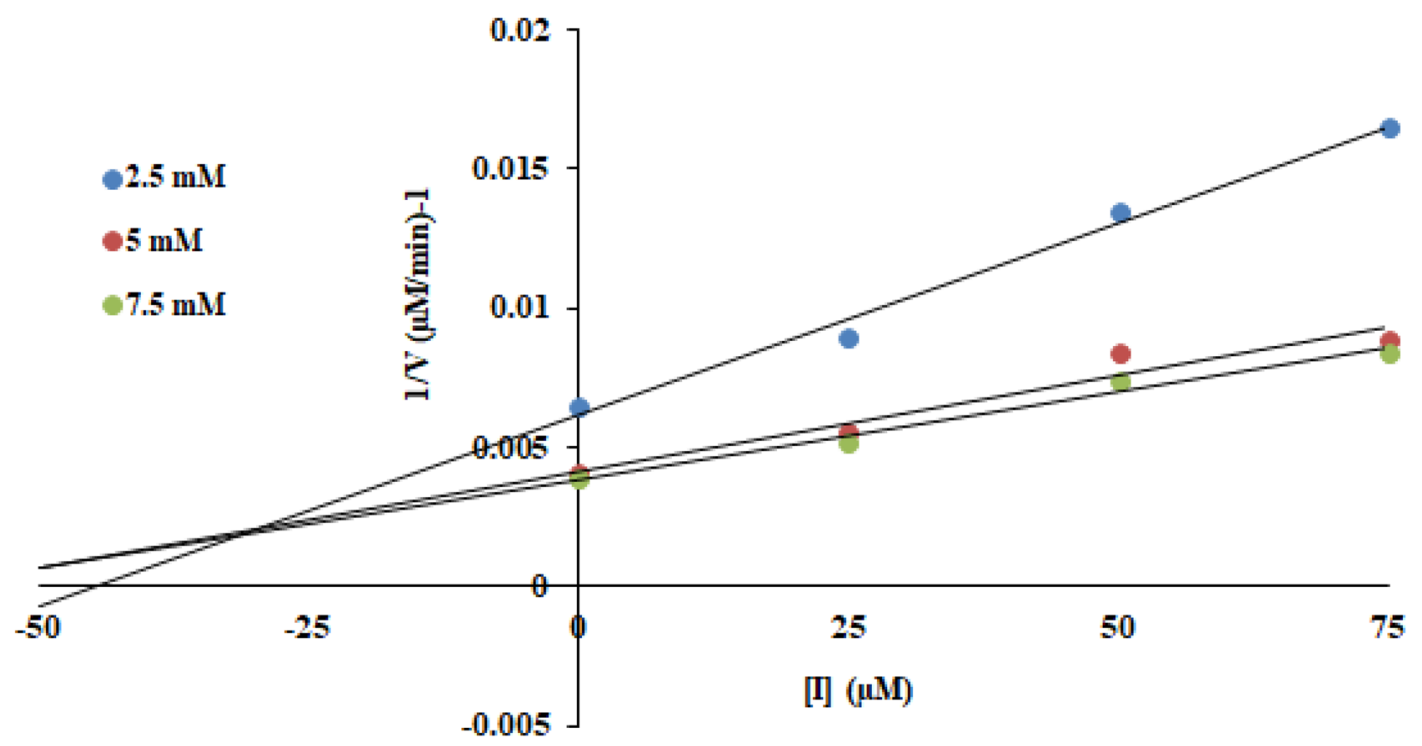

Fig. 2 A Inhibitory type determination of $\mathbf{4}$ using Lineweaver-Burk plot on tyrosinase. B Inhibitory constant $\left(K_{i}\right)$ value determination of $\mathbf{4}$ using Dixon plot on tyrosinase

\section{Plasmid DNA damage effects of isolated compounds}

Supercoiled plasmid DNA damage effects of the isolated compounds were investigated using agarose gel electrophoresis. The electrophoresis image is shown in Fig. 3.
As shown in Fig. 3, the amounts of supercoiled form were similar in the presence of the isolated compounds and the tested compounds did no cleavage actions at 100 and $200 \mu \mathrm{M}$. This is considered as an indication that the compounds are non-toxic at the concentrations studied. 


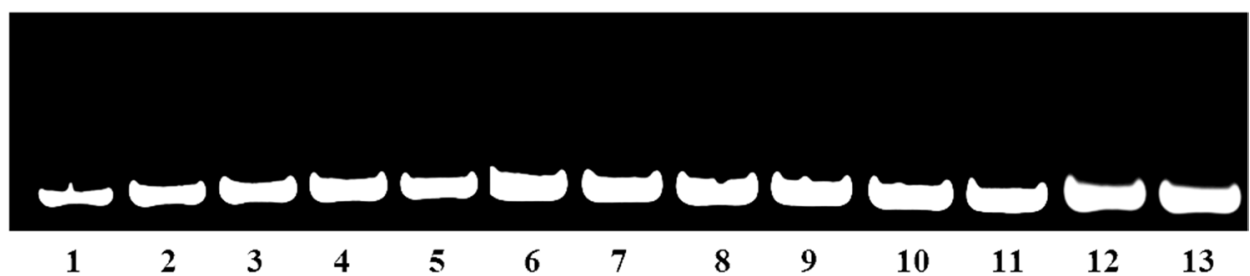

Fig. 3 Plasmid DNA damage effects of the isolated compounds. Lane 1: DNA control; lanes 2-3: DNA +5 $(100 \mu \mathrm{M}, 200 \mu \mathrm{M})$; lanes 4-5: DNA + $1(100 \mu \mathrm{M}, 200 \mu \mathrm{M})$; lanes 6-7: DNA + $2(100 \mu \mathrm{M}, 200 \mu \mathrm{M})$;

\section{Molecular modelling}

\section{Evaluation of druglikeness and ADMET}

Bad ADMET profile partly accounts for high attrition rates in clinical stages of drug design. A set of molecular descriptors and pharmacokinetic parameters were evaluated to predict the potential of the compounds regarding eligibility for clinical use. Among several descriptors, molecular weight, number of rotatable bonds, hydrogen donor and acceptor counts, $\log \mathrm{P}$, and polar surface area are considered relevant to druglikeness. According to QikProp, molecular weight and number of rotatable bonds of the compounds were within the limits defined for druglike chemical space $[25,26]$. Hydrogen donor count of compounds $\mathbf{2}, \mathbf{3}$, and $\mathbf{4}$, and hydrogen acceptor count of $\mathbf{3}$ were higher than the optimal values, showing too many atoms with hydrogen bond capacity (see Table S1 of the Supplementary material). This also led to PSA values slightly over the limit for these compounds and too low $\log P$ value for 3. QikProp could not calculate descriptors for $\mathbf{6}$ due to the quaternary ammonium present in its structure. Altogether, these results highlight the polar nature of the metabolites and possible difficulties in terms of membrane lanes 8-9: DNA+3 $(100 \mu \mathrm{M}, 200 \mu \mathrm{M})$; lanes 10-11: DNA+6 $(100 \mu \mathrm{M}, 200 \mu \mathrm{M})$; lanes 12-13: DNA + 4 $(100 \mu \mathrm{M}, 200 \mu \mathrm{M})$

diffusion. These properties can be optimized through semisynthetic derivatives.

On the other hand, the compounds were predicted to have a number of favorable properties. According to QikProp and SwissADME, the compounds were water-soluble and penetrable to skin, which is crucial considering the uses of tyrosinase inhibitors. According to SwissADME, the compounds generally were not likely to inhibit common cytochrome P450 enzymes with exceptions such as CYP3A4. Unlike others $\mathbf{3}$ and $\mathbf{4}$ were not predicted as substrates of Pgp (see Table S1 and S2 of the Supporting information for details). Cytochrome P450 inhibition and Pgp affinity usually cause undesired drug-drug interactions.

\section{Molecular modelling of tyrosinase inhibition}

The compounds except 3 were docked to the tyrosinase active site, which features two catalytic copper ions, each of which chelates with three histidine residues. 4 fit in the active site with a very high affinity (Table 2) obtaining the best docking score in the series. Scoring terms of $\mathbf{4}$ showed that the compound forms strong polar and van der Waals contacts, as well as H-bond interactions (represented by Coulomb, van der Waals, and H-bond energy, respectively) with the receptor at
Table 2 Molecular docking and MM-GBSA terms for $\mathbf{1 , 2 , 4}$, 5 , and 6

\begin{tabular}{|c|c|c|c|c|c|}
\hline Compound & $\begin{array}{l}\text { Docking score } \\
(\mathrm{kcal} / \mathrm{mol})\end{array}$ & $\operatorname{Ecoul}^{\mathrm{a}}(\mathrm{kcal} / \mathrm{mol})$ & $\mathrm{evdW}^{\mathrm{b}}(\mathrm{kcal} / \mathrm{mol})$ & $\begin{array}{l}\text { XP HBond } \\
(\mathrm{kcal} / \mathrm{mol})\end{array}$ & $\begin{array}{l}\Delta \mathrm{G} \text { bind }^{\mathrm{d}} \\
(\mathrm{kcal} / \\
\text { mol })\end{array}$ \\
\hline 1 & -7.3 & -13.7 & -40.1 & -2.7 & -28.1 \\
\hline 2 & -7.7 & -12.3 & -40.9 & -3.4 & -21.8 \\
\hline 4 & -9.0 & -13.1 & -40.8 & -4.7 & -27.5 \\
\hline 5 & -6.1 & -8.3 & -25.0 & -0.5 & 3.1 \\
\hline 6 & -4.4 & -8.3 & -22.3 & -1.4 & -32.4 \\
\hline Kojic acid & -4.0 & -7.9 & -22.1 & -0.9 & -14.1 \\
\hline
\end{tabular}




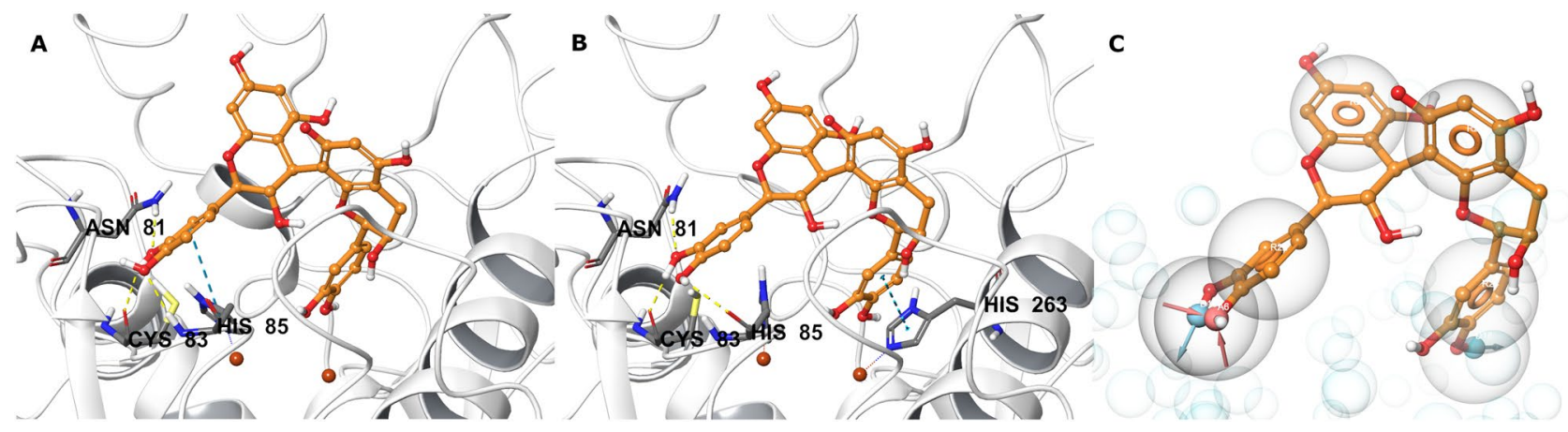

Fig. 4 Predicted binding mode of 4 with tyrosinase (A), the optimized binding mode following MM-GBSA calculations (B), and the pharmacophore model of $\mathbf{4}$ created from the predicted 4-tyrosinase complex (C). For A and B, $\mathbf{4}$ is represented as color stick-balls, the protein residues as gray sticks, protein backbone as white cartoon, and the key interactions as color dashes. For $\mathrm{C}$, feature boundaries are represented as gray spheres, H-bond donor and acceptor features as arrows, ring feature as rings, and receptor atoms (excluded volumes) as blue spheres the same time. 4 was almost the best compound regarding all the three terms.

In the predicted binding mode of $\mathbf{4}$, the dihydroxyphenyl rings reached to the bottom of the active site gorge close to the catalytic copper ions. One of the dihydroxyphenyl rings engaged in extensive $\mathrm{H}$ bonds with the active site residues, namely His85, one of the copper ligands, Asn81 and Cys83. The other dihydroxyphenyl ring positioned close to the copper ions with the hydroxyl groups pointing to them (Fig. 4A). The binding interaction diagram also shows how $\mathbf{4}$ effectively engages with the active site residues through polar interactions with Thr84, His244, Glu256, His259, Asn260, His263, Thr324, as well as hydrophobic interactions with Phe90, Val248, Phe264, Met280, Val283, Ala286, and Phe292 (see Fig. S6 of the Supplementary material).

The ligand-tyrosinase complexes obtained from molecular docking were further evaluated via MM-GBSA calculations to account for solvation effects, which is ignored during docking. The $\Delta \mathrm{G}$ bind term in Table 2 reflects how favorable the complex is in the solvated environment and 4-tyrosinase complex was found compatible with solvent effects. During the MMGBSA run, the complex was optimized by applying conformational flexibility to the receptor residues in close contact with the ligand. This allowed additional interaction between 4 and His263, another copper ligand (Fig. 4B). The pharmacophore model created from the optimized 5-tyrosinase complex further highlighted the importance of the hydroxyl groups of the dihydroxyphenyl moieties for H-bond interactions, as well as the $\mathrm{A}$ and $\mathrm{B}$ rings of the catechin moieties for van der Waals contacts (Fig. 4C).

\section{Conclusions}

The findings in this study clearly indicate that Z. jujuba is an important source for pharmaceutical investigations. $n$-BuOH extract $(25.03 \pm 0.77 \mu \mathrm{g} / \mathrm{mL})$ and water extract exhibited higher inhibitory effect than that of acarbose as a positive control $(46.10 \pm 2.30 \mu \mathrm{g} / \mathrm{mL})$. Although the isolated compounds showed $\alpha$-glucosidase inhibitory effects to some extent, their $\alpha$-glucosidase inhibitory effects were not better than the extract itself, indicating synergistic effects of different compounds in the extract. Compound 4 exhibited the best tyrosinase inhibitory effect, which is similar to the positive control, kojic acid. Moreover, the kinetic analysis revealed that it is a competitive inhibitor of tyrosinase. Our in vitro studies were consistent with in silico studies. 4 was found to fit in the active site of tyrosinase with a very high affinity according to molecular docking and MM-GBSA scores. Furthermore, druglikeness and ADMET calculations showed that the isolates are expected to possess favorable pharmacokinetic properties including good skin penetration, a crucial factor in the development of tyrosinase inhibitor cosmetic products.

Supplementary Information The online version contains supplementary material available at https://doi.org/10.1007/s00217-021-03946-0.

Funding A part of this study was supported by Hacettepe University Scientific Research Projects Coordination Unit [Project Number: THD2019-17976]. The authors wish to thank the Scientific Grant Agency of the Slovak Republic VEGA [Project Number: 1/0116/22]. This publication was created with the support of the Operational Program 
Integrated Infrastructure for the project: Development of products by modification of natural substances and study of their multimodal effects on COVID-19, ITMS: 313011ATT2, co-financed by the European Regional Development Fund.

\section{Declarations}

Conflict of interest The authors declare that they have no known competing financial interests or personal relationships that could have appeared to influence the work reported in this paper.

Ethics approval Multiple biological effects of secondary metabolites of Ziziphus Jujuba: isolation and mechanistic insights through in vitro and in silico studies does not contain any studies with human or animals.

\section{References}

1. Liu S-J, Lv Y-P, Tang Z-S, Zhang Y, Xu H-B, Zhang D-B, Cui C-L, Lui H-B, Sun H-H, Song Z-X, Wei S-M (2021) Ziziphus jujuba Mill., a plant used as medicinal food: a review of its phytochemistry, pharmacology, quality control and future research. Phytochem Rev 20(3):507-541

2. Lu Y, Bao T, Mo J, Ni J, Chen W (2021) Research advances in bioactive components and health benefits of jujube (Ziziphus jujuba Mill.) fruit. J Zhejiang Univ Sci B 22(6):431-449

3. Solano F (2014) Melanins: skin pigments and much more-types, structural models, biological functions, and formation routes. New J Sci. https://doi.org/10.1155/2014/498276

4. IDF DIABETES ATLAS (2021) https://diabetesatlas.org/idfawp/ resource-files/2021/07/IDF_Atlas_10th_Edition_2021.pdf Accessed 12 Dec 2021

5. Şöhretoğlu D, Sari S, Barut B, Ozel A (2018) Discovery of potent alpha-glucosidase inhibitor flavonols: Insights into mechanism of action through inhibition kinetics and docking simulations. Bioorganic Chem 79:257-264

6. Şöhretoğlu D, Sari S, Barut B, Ozel A (2018) Tyrosinase inhibition by some flavonoids: Inhibitory activity, mechanism by in vitro and in silico studies. Bioorgan Chem 81:168-174

7. Butterworth PJ (1972) The use of Dixon plots to study enzyme inhibition. Biochim Biophys Acta 289(2):251-253

8. Barut B, Demirbaş Ü (2020) Synthesis, anti-cholinesterease, $\alpha$-glucosidase inhibitory, antioxidant and DNA nuclease properties of non-peripheral triclosan substituted metal-free, copper(II), and nickel(II) phthalocyanines. J Organomet Chem 923:121423

9. Lu C, Wu C, Ghoreishi D, Chen W, Wang L, Damm W, Ross GA, Dahlgren MK, Russell E, Von Bargen CD, Abel R, Friesner RA, Harder ED (2021) OPLS4: improving force field accuracy on challenging regimes of chemical space. J Chem Theory Comput 17:4291-4300

10. Daina A, Michielin O, Zoete V (2017) SwissADME: a free web tool to evaluate pharmacokinetics, drug-likeness and medicinal chemistry friendliness of small molecules. Sci Rep 7:42717

11. Ismaya WT, Rozeboom HJ, Weijn A, Mes JJ, Fusetti F, Wichers HJ, Dijkstra BW (2011) Crystal structure of Agaricus bisporus mushroom tyrosinase: identity of the tetramer subunits and interaction with tropolone. Biochemistry 50(24):5477-5486
12. Berman HM, Westbrook J, Feng Z, Gilliland G, Bhat TN, Weissig H, Shindyalov IN, Bourne PE (2000) The protein data bank. Nucleic Acids Res 28(1):235-242

13. Sastry GM, Adzhigirey M, Day T, Annabhimoju R, Sherman W (2013) Protein and ligand preparation: parameters, protocols, and influence on virtual screening enrichments. J Comput Aided Mol Des 27(3):221-234

14. Friesner RA, Murphy RB, Repasky MP, Frye LL, Greenwood JR, Halgren TA, Sanschagrin PC, Mainz DT (2006) Extra precision glide: docking and scoring incorporating a model of hydrophobic enclosure for protein-ligand complexes. J Med Chem 49(21):6177-6196

15. Jacobson MP, Pincus DL, Rapp CS, Day TJ, Honig B, Shaw DE, Friesner RA (2004) A hierarchical approach to all-atom protein loop prediction. Proteins 55(2):351-367

16. Dixon SL, Smondyrev AM, Knoll EH, Rao SN, Shaw DE, Friesner RA (2006) PHASE: a new engine for pharmacophore perception, 3D QSAR model development, and 3D database screening: 1. Methodology and preliminary results. J Comput Aided Mol Des 20(10-11):647-671

17. Rastrelli L, Saturnino P, Schettino O, Dini A (1995) Studies on the constituents of Chenopodium pallidicaule (Canihua) seeds. Isolation and characterization of two new flavonol glycosides. J Agric Food Chem 43(8):2020-2024

18. Khallouki F, Haubner R, Ricarte I, Erben G, Klika K, Ulrich CM, Owen RW (2015) Identification of polyphenolic compounds in the flesh of Argan (Morocco) fruits. Food Chem 179:191-198

19. Renda G, Özel A, Barut B, Korkmaz B, Šoral M, Kandemir Ü, Liptaj T (2017) Bioassay guided isolation of active compounds from Alchemilla barbatiflora Juz. Records Nat Prod 12:76-85

20. Wiesneth S, Petereit F, Jürgenliemk G (2015) Salix daphnoides: a screening for oligomeric and polymeric proanthocyanidins. Molecules 20(8):13764-13779

21. Bhandari DM, Fedoseyenko D, Begley TP (2016) Tryptophan lyase (NosL): a cornucopia of 5'-deoxyadenosyl radical mediated transformations. J Am Chem Soc 138(50):16184-16187

22. Barbosa-Filho J, Da-Cunha EVL, Cornélio ML, Silva Dias CD, Gray AI (1997) Cissaglaberrimine, an aporphine alkaloid from Cissampelos glaberrima. Phytochemistry 44(5):959-961

23. Pelley JW (2012) Enzymes and Energetics. In: Pelley JW (Ed.), Elsevier's Integrated Review Biochemistry Elsevier.

24. Song W, Liu LL, Ren YJ, Wei SD, Yang HB (2020) Inhibitory effects and molecular mechanism on mushroom tyrosinase by condensed tannins isolation from the fruit of Ziziphus jujuba Mill. Var. spinosa (Bunge) Hu ex H F. Chow. Int J Biol Macromol 165(Pt B):1813-1821

25. Lipinski CA, Lombardo F, Dominy BW, Feeney PJ (2001) Experimental and computational approaches to estimate solubility and permeability in drug discovery and development settings. Adv Drug Deliv Rev 46(1-3):3-26

26. Veber DF, Johnson SR, Cheng HY, Smith BR, Ward KW, Kopple KD (2002) Molecular properties that influence the oral bioavailability of drug candidates. J Med Chem 45(12):2615-2623

Publisher's Note Springer Nature remains neutral with regard to jurisdictional claims in published maps and institutional affiliations. 